cycads, screw pines, palms, orchids, figs, ebonies, the gorgeous Amherstia, and many other tropical trees grow luxuriantly.

All in all, Jamaica probably offers the botanist as great a variety of tropical conditions within a day's walk of Cinchona and a day's drive from Kingston as can be found anywhere in an area of this size. It is evident that the opportunities for the study of many kinds of botanical problems are abundant at Cinchona, Hope, and Castleton. In fact, there are many botanical problems of prime importance which can be studied only in such environments. ${ }^{\mathrm{x}}$

Any American botanist wishing to work at Cinchona may be granted this privilege by the Cinchona committee, consisting of N. L. BRITton, J. M. Coulter, and D. S. Johnson. Inquiries for this privilege and for information regarding the conditions under which it may be granted should be sent to the writer.-D. S. JoHnson, Johns Hopkins University, Baltimore, $M d$.

\title{
CHROMOSOME NUMBER IN THE SEQUOIAS
}

For some years, we have been concerned with cytological studies in the genus Sequoia. In particular a review of the evidence presented by LAwSON ${ }^{2}$ on the life history of $S$. sempervirens has been attempted. That considerable interest attaches to this genus is obvious, and certainly the information available in regard to the life history of $S$. gigantea is meager. The present note is intended primarily to call attention to certain points which have been indicated in our preliminary studies.

LAwSON reports that, in his material collected at Stanford University, California, the pollen grains are formed during the second or third week of December, and that the pollen is shed during the first week of January. ${ }^{3}$ In our experience, extending over some three years, the pollen is often mature in September and rarely is it found on the tree after November. Our observations have been made on trees of the same size growing in three different localities: Berkeley, Redwood Peak, and Mill Valley, California. There is great variation in the time of pollen shedding. Two trees standing side by side may show a difference of two weeks to a month in the occurrence of this phenome-

${ }^{x}$ For further details see Science 43:917. 1916, and Popular Science Monthly, January, I9I5.

${ }^{2}$ Lawson, A. A., The gametophytes, archegonia, fertilization, and embryo of Sequoia sempervirens. Ann. Botany 18: 1-28. 1904.

${ }^{3}$ Shaw, W. R., Contribution to the life history of Sequoia sempervirens. Bот. GAZ. $21: 332-339$. 1896. 
non, and in any two consecutive seasons an individual tree may shed pollen on dates separated by a corresponding interval of time. In the same way it has been found impossible to predict with any degree of accuracy the time of occurrence of any of the significant stages in maturation, and this fact has rendered more difficult the determination of chromosome number in $S$. sempervirens. Numerous efforts so far have failed to discover the reduction divisions in the microspore mother cells.

As to chromosome number in $S$. sempervirens, LAwson remarks that "as near as could be estimated, there are 16 chromosomes in the gametophyte and 32 in the sporophyte." In recent tabulations of chromosome numbers in plant species, 45 gymnosperms are listed. All but $\mathrm{I} 2$ of these have $x \mathrm{I} 2$, and $2 x_{24}$, and of these $\mathrm{I} 2\left(\begin{array}{ll}x_{\mathrm{I}} 6 \\ \mathrm{and}\end{array} 2 x_{32}\right)$ a number are listed as doubtful. On this basis perhaps there might be legitimate ground to question Lawson's count. In sections of root tips of $S$. sempervirens we have made counts which only in rare instances confirm Lawson's report. The difficulties are great in such material, however. In corresponding and more favorable material of $S$. gigantea, we have uniformly counted from 2 I to 24 chromosomes, but never a greater number.

With these facts in mind, the following possibilities present themselves. First, if Lawson's count is correct for S. sempervirens and if our count is correct for $S$. gigantea, the two species have different chromosome numbers. Second, if our suspicion of Lawson's count in S. sempervirens is valid and if our count in $S$. gigantea is correct, both species have $x$ I 2 and $2 x 24$. The third possibility involves an inaccuracy in our count of $S$. gigantea and chromosome numbers 16 and 32 for both species. In our opinion the second possibility is the only one which merits serious consideration. It seems worth while, however, to present the whole situation, since the other possibilities cannot wholly be left out of account with the data at hand. Further studies will involve an investigation of the life history of $S$. gigantea and the obtaining of a final conclusion as to chromosome number in $S$. sempervirens.-T. H. Goodspeed and M. P. CRANe, University of California. 